\title{
Degradation of the elastic modulus of cement-based grouting material with early ages after fire
}

\author{
Qingtao Li ${ }^{\mathrm{a}, \mathrm{b}}$, Lujie Liu ${ }^{\mathrm{a}}$, Zhaohui Huang ${ }^{\mathrm{c}, *}$, Guanglin Yuan $^{\mathrm{a}}$
}

a State Key Laboratory for Geomechanics \& Deep Underground Engineering, School of Mechanics \& Civil Engineering, China University of Mining \& Technology, Xuzhou, Jiangsu 221116, China

b Jiangsu Collaborative Innovation Center for Building Energy Saving and Construction Technology, Xuzhou, Jiangsu 221116, China

c Department of Civil and Environmental Engineering, College of Engineering, Design and Physical Sciences, Brunel University, Uxbridge, Middlesex UB8 3PH, UK

\begin{abstract}
This paper presents a comprehensive experimental investigation on the degradation of the elastic modulus of cement-based grouting materials with different early curing ages after exposed to high temperature. The research focused on the influences of different temperatures, curing ages, water mixing ratio and cooling methods on the residual elastic modulus of the material. Test results indicate that the residual elastic modulus of cement-based grouting material reduces significantly after heating. The degradation of the residual elastic modulus of the material increases with increasing water mixing ratio. However, the influence of water mixing ratio is not very significant. The research indicates that the models proposed in Eurocode 2, the Chinese code and ACI-216 for normal concrete are not suitable to predict the degradation of the residual elastic modulus of cement-based grouting materials exposed to fire.
\end{abstract}

Keywords: Cement-based grouting material; Curing age; Water mixing ratio; Elastic modulus; Fire.

\footnotetext{
*Corresponding author, E-mail address: zhaohui.huang@brunel.ac.uk (Z. Huang)
} 


\section{RESEARCH HIGHLIGHTS:}

$>$ Study the degradation of the residual elastic modulus of CGM after fire.

Investigate the influence of temperatures on the elastic modulus of CGM.

Assess the influences of the parameters on the residual elastic modulus of CGM.

$>$ Generate a set of valuable test data for the researches and structural engineers. 


\section{Introduction}

In recent years, cement-based grouting material (CGM) has received considerable attentions from structural engineers and researchers due to the material has super early strength, fluidity, no shrinkage and convenient for construction [1-5]. The research conducted by Li et al. [6] indicates that temperature and water mixing ratio are main factors which affect the residual compressive strength of CGM after fire. The higher exposed temperature the lower residual compressive strength. The reduction of the residual compressive strength of the material increases with increasing water mixing ratio.

The elastic modulus of normal concrete with different curing ages at ambient temperature has been extensively studied by many researchers. Shen et al. [7] indicated that the elastic modulus of the concrete in early curing age increases with time, but the growth speed decreases against time. Zhou et al. [8] found that the growth rate of the elastic modulus of concrete before 7 days curing age is higher than the one after 7 days curing age. Li et al. [9] pointed out that the elastic modulus of concrete increases with increasing maximum aggregate size or reducing water cement ratio. The research conducted by Vilardell et al. [10] indicated that the elastic modulus of concrete increased with the increase of concrete age, and the growth rate of the specimens before the age of 28 days is higher than the one after 28 days. Shen et al. [11] found that when concrete curing age was less than 7 days, the Young's modulus of the concrete was about 1.0 to 1.3 times that of the elastic modulus of the concrete.

Shariq et al. [12] found that for normal concrete and the concrete with $40 \%$ of slag their elastic moduli were increased by $16 \%$ and $22 \%$, respectively from the concrete with ages of 28 days to 180 days. $\mathrm{Li}$ et al. [13] indicated that with the increase of curing temperature $\left(20,35,50,70{ }^{\circ} \mathrm{C}\right)$, the elastic modulus of concrete decreased, also the elastic modulus of concrete decreased with increasing the diameter of fine aggregate or water cement ratio. Crouch et al. [14] found that the elastic modulus of the concrete with the porosity of $23 \%$ to $31 \%$ is higher than the concrete with other porosity. Parra et al. [15] pointed out that the elastic modulus of normal concrete is smaller than the one of self-compacting concrete and the difference increases with increasing concrete age. Wongpa et al. [16] studied the relationship between the elastic modulus and compressive strength of concrete and found that there is a linear relationship between the elastic modulus and square root of 
compressive strength for normal concrete.

Many researchers investigated the effects of high temperature on concrete elastic modulus [17-22]. The results indicated that the elastic modulus of concrete reduces with increasing temperature gradually. The main reasons are that high temperature results the decomposition of hydration products within concrete and the destruction of the binding key with the microstructure of concrete. The degradation of elastic modulus at high temperature depends on concrete moisture loss, high temperature creep and aggregate type. Kim et al. [20] found that the elastic modulus of concrete, after exposed to $100{ }^{\circ} \mathrm{C} \sim 300{ }^{\circ} \mathrm{C}$, reduced $10 \% \sim 20 \%$ of its value at ambient temperature. After exposed to $700{ }^{\circ} \mathrm{C}$ the elastic modulus of concrete reduced to $45 \% \sim 50 \%$ of its value at ambient temperature. Evandro et al. [18] found that after exposed to $600{ }^{\circ} \mathrm{C}$, the elastic modulus of normal strength concrete reduced $51 \%$ of its value at ambient temperature and the residual elastic modulus of high strength concrete was about $41 \%$ of its original value at room temperature.

In recent years, due to some problems related to the organization and management of the construction site, there were considerable numbers of fires happened during the construction period of buildings $[23,24]$. When fire accident happens during the period of construction, the mechanical properties of the concrete in early age (which has not yet reached design strength of the material) will be significantly changed. Therefore, for assessing the structural safety of the building after fire it is really important to understand the mechanical properties of such early age of concrete after exposed to fire.

As mention above, considerable researches have been done on the material properties of normal concrete with early curing ages after exposed to fire. The residual compressive strength of early age cement-based grouting materials after fire has been recently investigated by the authors [6]. However, according to the authors' knowledge there are very limited researches on the residual elastic modulus of early age cement-based grouting materials after exposed to high temperatures. Because of the cement-based grouting material has high compressive strength in the early stage of construction, its elastic modulus is considerably different compared to normal concrete. Hence, it is needed to understand the elastic modulus of the early age cement-based grouting material after exposed to fire. This information is very important for structural engineers to assess the structural safety and repair ability after fire. Therefore, the main objectives of this research are: 
- Conduct a series of tests to investigate the degradation of the elastic modulus of cement-based grouting materials after exposed to different temperatures.

- Study the influence of temperatures on the residual elastic modulus of cement-based grouting materials.

- Investigate the influences of different curing ages and water mixing ratios on the residual elastic modulus of cement-based grouting materials.

- Generate a set of valuable test data for the fellow researches and practical structural engineers who are interested in repairing and strengthening of reinforced concrete buildings.

\section{Experimental program}

\subsection{Test specimens}

In this research the cement-based grouting material was produced by Zhengzhou Nuweison Construction Engineering Technology Ltd. This cement-based grouting material (CGM-1) had high-strength and no shrinkage. The physical compositions and properties are presented in Tables 1 and 2, respectively. Table 3 shows the compositions of additive binding gelled material used. Based on the recommendations proposed in Chinese design code for cementitious grouting material [25], four key design curing ages of 3, 7, 14, and 28 days before heating were adopted in this study. The outcomes of previous researches $[26,27]$ indicated that when cementitious materials were heated up to $600{ }^{\circ} \mathrm{C}$, the compressive strength of the materials was significantly degraded. Therefore, it is reasonable to assume that the concrete structural members after exposed to such high temperature are unrepairable. Hence, in this research three level temperatures of $150{ }^{\circ} \mathrm{C}, 350{ }^{\circ} \mathrm{C}$ and $550{ }^{\circ} \mathrm{C}$ were used. Reference [4] pointed out that the water mixing ratio of cement-based grouting materials is an important factor which needs to be considered. Hence, three water mixing ratios of $12 \%, 14 \%$ and $16 \%$ were adopted in this research. For engineering practice, water is used to extinguish a fire, so in this study the influences of water cooling and natural air cooling (natural cooling) on the residual elastic modulus were investigated. As shown in Table 4 the test specimens were divided into 72 groups. The size of the test specimens was $100 \mathrm{~mm} \times 100 \mathrm{~mm} \times 300 \mathrm{~mm}$. 


\subsection{Test procedure}

For this study, an electrical heating furnace GWD-05 with power of $30 \mathrm{~kW}$ was used to heat the specimens. The inside dimensions of the furnace are $2000 \mathrm{~mm} \times 600 \mathrm{~mm} \times 400 \mathrm{~mm}$. The furnace has computerized temperature control system. For representing a real fire, high heating ratio was adopted. The heating rate of $10{ }^{\circ} \mathrm{C} / \mathrm{min}$ was used for all tests [28]. In order to make sure the temperature within the specimens was uniformly distributed, the specimens were heated to the target temperature then the target temperature was kept constant for $90 \mathrm{~min}$. The uniform targeted temperature within the specimens can be achieved using this heating method in the authors' previous research [6].

After the specimens were cast for 24 hours, the molds of specimens were dismantled then the specimens were placed in a standard curing room with temperature of $20 \pm 2{ }^{\circ} \mathrm{C}$ and more than $95 \%$ of relative humidity [29]. In order to eliminate the influence of the free water on the surface of the specimens, the specimens were cured until one day before required curing age, then the specimens were naturally dried for one day before heating. After heating the specimens were cooled down to ambient temperature under natural cooling or water cooling conditions. Then the specimens were stored in the normal lab conditions $\left(20^{\circ} \mathrm{C}\right.$ and R.H. $\left.=95 \%\right)$ until total curing time of 28 days (curing time before heating + curing time after heating) to be reached. Then the specimens were tested to generate the elastic modulus of the specimens.

For measuring the axial compressive strength and elastic modulus of the specimens, a YAW-3000 type electro-hydraulic servo pressure tester was used. The test procedure was based on the specification of Chinese standard [29]. Firstly, specimens' surface and upper and lower bearing board were cleared. Then axial compressive strength and elasticity modulus of specimens were tested. During the test, axis of the specimens should be aimed at the centre line of the press table of the compression-testing machine, as shown in Fig. 1(a). The load should be applied uniformly and consecutively (5 to $8 \mathrm{kN} / \mathrm{s}$ ). As shown in Fig. 1(b), for the elasticity modulus test, modulus tester should be installed on the midline of the specimens' both sides and should be asymmetrical. According to [29] one third of axial compressive strength was used as a reference point to determine the elastic modulus of the specimens. For each test group, three identical specimens were used to measure the elastic modules, then the average elastic modulus of the three specimens was calculated to represent the elastic modulus of that group. 
For comparison, the specimens with different water-to-cement based grouting material ratios (here called water mixing ratios) at the curing age of 28 days without heating were tested. The axial compressive strengths of the specimens $(100 \mathrm{~mm} \times 100 \mathrm{~mm} \times 300 \mathrm{~mm})$ with the water mixing ratios of $12 \%, 14 \%, 16 \%$ were $62.3 \mathrm{MPa}, 53.8 \mathrm{MPa}, 48.1 \mathrm{MPa}$, respectively. The elastic modulus of the specimens with the water mixing ratios of $12 \%, 14 \%, 16 \%$ were $42.8 \times 10^{3} \mathrm{MPa} 、 37.0 \times 10^{3} \mathrm{MPa}$ 、 $30.4 \times 10^{3} \mathrm{MPa}$, respectively.

\section{Results and discussions}

Table 5 gives the tested average residual elastic moduli $\left(E_{\mathrm{c}, \mathrm{T}}\right)$ of 72 group under different conditions. The total curing time of different specimens was 28 days (curing time before heating + curing time after heating). The residual compressive strength of cement-based grouting material with early ages after fire has been studied separately in the authors' previous research and was presented in [6].

\subsection{Influence of the curing age before heating on the residual elastic modulus}

For representing the degradation of the residual elastic modulus of heated cement-based grouting material with different curing ages before heating, the degradation ratio of residual elastic modulus after heating is defined as: $E_{c, T} / E_{c, 20}$, in which $E_{c, 20}$ is 28 days' elastic modulus at ambient temperature. Figs. 2 and 3 show the comparisons of the degradation ratio $\left(E_{c, T} / E_{c, 20}\right)$ against the different curing ages before heating for the specimens with three water mixing ratios under natural cooling or water cooling after exposed to three different high temperatures.

As shown in Figs. 2 and 3, the residual elastic moduli of the specimens with 7 days curing age before heating were the highest compared to other curing ages before heating under different exposed temperatures and water mixing ratios.

However, the residual elastic moduli of the specimens with 3 days curing age before heating were slightly larger than the one of the specimens with 14 and 28 days curing ages before heating. This is because the specimens with 3 days curing age before heating has had longer re-curing time after heating compared to the specimens with 14 and 28 days curing before heating. The re-curing time for the specimens with 3 days curing age after heating was 25 days. However, the re-curing time for the specimens with the curing age of 14 days and 28 days after heating were 14 and 0 days, respectively.

Also as shown in the SEM images of the specimens heated to the temperature of $550{ }^{\circ} \mathrm{C}$ with 
different curing ages before heating (Fig. 3 of the authors' paper [6]), it is clear that after heating the hydration products within the specimen with 3 days curing age before heating were more than the one of the specimens with 14 or 28 days curing ages before heating. The specimen with 28 days curing age before heating showed least remnants of the hydration products and more cracks formed within the specimen. It also can be seen that the elastic moduli of the specimens with 28 days curing age before heating were the lowest. The results indicated that the exposed temperature has significant impact on the degradation of the residual elastic moduli of cement-based grouting material.

For example, Fig. 2 (a) shows the degradation ratios of the residual elastic moduli against different curing ages before heating for the specimens with the water mixing ratio of $12 \%$ under natural cooling condition. From the figure it is clear that after exposed to the temperature of $150{ }^{\circ} \mathrm{C}$ the residual elastic moduli of the specimens with 3, 7, 14, 28 days curing ages before heating were reduced by $34 \%, 29 \%, 36 \%, 36 \%$, respectively compared to the specimens without heating. But, for the specimens exposed to the temperature of $550^{\circ} \mathrm{C}$, the residual elastic moduli of the specimens with $3,7,14,28$ days curing ages before heating were reduced by $58 \%, 60 \%, 64 \%$ and $64 \%$, respectively.

In order to explain the test results, the microstructure analyses of typical heated specimens were performed. As shown in Fig. 3(b) of the authors' paper [6], for the specimen with 7 days curing age before heating, there were a lot of remnants of hydration products within the specimen. These hydration products filled the part of cracks resulted from high temperature. Compared to Figs. 3(a) and 3(b) of the authors' paper [6], it is clear that the remnants of hydration products within the specimen with 7 days curing age before heating were much more than the one of the specimen with 3 days curing age before heating. For the specimen with 3 days curing age before heating, the internal structure was loose due to the thermal decomposition of hydrated cement paste during heating and the water was more easily to escape within the specimen. In contrast, the specimen with 7 days curing age before heating had more compact internal structure with a high degree of hydration, and the water was more difficult to escape from the specimen. Therefore, during curing period after heating there was enough water for the further cement hydrations to be continued within the specimen. However, for the specimen with 3 days curing age before heating, there was less water available for continuing cement hydrations due to significant loss of water during the heating process. Hence, the remnants of hydration products within the specimen were much less compared to the 
specimen with 7 days curing age before heating.

Compared Fig. 3(a) with Figs. 3(c) and 3(d) of the authors' paper [6], it can been seen that after heating the hydration products within the specimen with 3 days curing age before heating were more than the one of the specimens with 14 or 28 days curing ages before heating. The specimen with 28 days curing age before heating showed least remnants of the hydration products and more cracks formed within the specimen. Therefore, the residual elastic moduli of the specimen with 7 days curing age before heating was the highest compared to the specimens with 3,14 and 28 days curing ages before heating. And the residual elastic moduli of the specimen with 28 days curing age before heating were the lowest.

\subsection{Influence of exposed temperatures on the residual elastic modulus}

Figs. 4 and 5 show the relationships of the degradation ratio of residual elastic modulus $\left(E_{c, T} / E_{c, 20}\right)$ after heating against the exposed temperatures for the specimens under different conditions. It is clear that the residual elastic moduli of the specimens were reduced with the increasing exposed temperature. The general degradation trends of residual elastic moduli were similar for the specimens with different water mixing ratios and cooling methods. As an example, Fig. 4 (a) shows the degradation of residual elastic moduli against exposed temperatures for the specimens with 3 day curing ages before heating and $12 \%$ water mixing ratio under natural cooling condition. The residual elastic moduli of the specimens exposed to $150{ }^{\circ} \mathrm{C} 、 350{ }^{\circ} \mathrm{C} 、 550{ }^{\circ} \mathrm{C}$ were reduced by $34 \%, 50 \%, 60 \%$ compared to the value at ambient temperature.

Fig. 5 of the authors' paper [6] shows the SEM images of the unheated and heated $\left(550{ }^{\circ} \mathrm{C}\right)$ specimens with 28 days curing age before heating and the water mixing ratio of $12 \%$. From Fig. 5(a) of the authors' paper [6] it can be seen that for the specimen without heating the structure of the material was intact and the hydration products were abundant. There were a large number of flocs which were C-S-H. However, as shown in Fig. 5(b) of the authors' paper [6], the specimen was heated to $550{ }^{\circ} \mathrm{C}$. It is clear that the flocs were reduced significantly and there were a lot of cracks formed within the material. That shows a substantial reduction of hydration products after heating to high temperature. After exposed to $550{ }^{\circ} \mathrm{C}$, the C-S-H gel within the specimens decomposed considerably; the dehydration of $\mathrm{Ca}(\mathrm{OH})_{2}$ generated $\mathrm{CaO}$; quartz crystal and quartz were transformed from stable $\alpha$ type to $\beta$ type quartz and the volume of the specimens were expanded 
rapidly [6]. All of these led to the considerably reduction of the residual elastic moduli of the specimens.

\subsection{Influence of water mixing ratios on the residual elastic modulus}

Figs. 6 and 7 show the relationships of the residual elastic modulus $\left(E_{c}, T\right)$ against the water mixing ratios for the specimens under different conditions. It can be seen from the figures that the general trends of the influences of water mixing ratios on the degradation of residual elastic modulus are similar for the specimens under different conditions. The residual elastic moduli of the specimens were reduced with increasing water mixing ratios. As indicated in previous researches, for cement-based material the elastic moduli of the material is generally reduced with increasing water mixing ratio. However, this research generated a valuable test data to assess the influence of water mixing ratio on the residual elastic modulus of cement-based grouting material with early ages after fire. Those data are useful for structural engineers who are interested in repairing and strengthening of reinforced concrete buildings using this material.

Fig. 7 of the authors' paper [6] shows the SEM images of the specimens of 7 days curing age before heating, with different water mixing ratios and exposed to $550{ }^{\circ} \mathrm{C}$ under natural cooling. As shown in Fig. 7(a) of the authors' paper [6], it is evident that the specimen with water mixing ratio of $12 \%$ had more hydration products which filled the cracks resulted from the heating. In contrast (see Fig. 7(c) of the authors' paper [6]), there were very little hydration products formed and a large number of cracks appeared inside the specimen with $16 \%$ water mixing ratio. This is because of the density of the specimen with lower water mixing ratio (12\%) was larger than the specimen with higher water mixing ratio $(16 \%)$. So the water within the specimen with water mixing ratio of $12 \%$ was difficult to escape from the material which was benefited to form more hydration products after heating. Therefore the residual elastic moduli of the specimens reduced with increasing water mixing ratios.

\subsection{Influence of cooling methods on the residual elastic modulus}

Fig. 8 shows the influences of cooling methods on the residual elastic moduli of the specimens under different conditions. It is interesting to note that for the specimens with 3, 7, 14 days curing ages before heating, the residual elastic moduli of the specimens using water cooling were greater compared to the specimens using natural cooling. However, for the specimens with 28 days curing age before heating, the residual elastic moduli of the specimens under water cooling were smaller than the specimens subjected to natural cooling. For water cooling, the temperature on the surface of 
the specimen was reduced suddenly which results high temperature gradient within the specimen. Hence, more cracks were formed within the specimen and the residual elastic modulus may reduce. However, water sprayed on the specimen compensates the moisture loss of the specimen during heating period. After heating the specimens with the curing ages of 3, 7, 14 days were further curing until reached to total curing age of 28 days. During this period some parts of C-S-H gel hydrate with water again and the hydration products fill some of the pore and cracks inside specimens. This is the main reason why the residual elastic moduli of the specimens under water cooling were higher than the specimens using natural cooling. But for the specimens with 28 days curing age before heating, the specimens were tested immediately after heating. Hence, there was no time for any further curing to occur within the specimens. Therefor the residual elastic moduli of those specimens with natural cooling were greater than the specimens under water cooling condition.

\section{Comparison with current design codes}

In this section the degradation of the residual elastic moduli of the specimens with 28 days curing age before heating were used to compare with Eurocode 2 [30], ACI-216 [31] and Chinese code [32]. Fig. 9 shows the comparisons of the degradation of the residual elastic modulus of the material (CGM) with different water mixing ratios of $12 \%, 14 \%, 16 \%$ exposed to high temperature between the test data and the predictions of different codes. It should be noted that the codes are for normal concrete. It can be seen that when the exposed temperature is lower than $200{ }^{\circ} \mathrm{C}$, the tested data are closed to the predictions of Eurocode 2, but the Chinese code over predicts the residual elastic moduli of cement-based grouting material. However, when the exposed temperature is high than $550{ }^{\circ} \mathrm{C}$, the predictions of the Chinese code are closed to the test data and Eurocode 2 under predicts the residual elastic moduli of cement-based grouting material. It is evident that ACI-216 significantly over predicts the residual elastic moduli of cement-based grouting material. Hence the models proposed in the current design codes for normal concrete are not suitable to predict the degradation of the residual elastic modulus of cement-based grouting material under fire conditions.

\section{Conclusions}

In this research a series of tests were conducted to study the residual elastic modulus of cement-based grouting materials after exposed to different temperatures. The main parameters 
considered for the specimens were curing ages before heating, water mixing ratios and cooling methods. Based on the test results the following conclusions can be drawn:

- The degradation of the residual elastic modulus of the specimen with 7 days curing age before heating was the smallest compared to other specimens with 3, 14, 28 days curing ages before heating. The reduction of the residual elastic modulus of the specimen with 28 days curing age before heating was the largest compared to other specimens.

- The residual elastic modulus of cement-based grouting material reduces considerably after heating. The higher exposed temperature the more reduction of residual elastic modulus of the material.

- The degradation of the residual elastic modulus of cement-based grouting material increases with increasing water mixing ratio. However, the influence of water mixing ratio is not very significant.

- Water cooling method can provide some extra moisture for the specimens after heating. This will help the specimens to regain some residual stiffness after exposed to high temperature.

- The test results indicate that the degradation of elastic modulus of cement-based grouting materials after exposed to high temperature is quite different compared with normal concrete. Therefore, the models proposed in Eurocode 2, the Chinese code and ACI-216 for normal concrete are not suitable to predict the degradation of the residual elastic modulus of cement-based grouting materials after fire.

- The test data produced in this research are very useful for practical structural engineers who are interested in repairing and strengthening of reinforced concrete buildings using this material.

\section{Acknowledgements}

This research has been financially supported by National Natural Science Foundation of China (Grant No. 51208504) and Research Fund of JiangSu Collaborative Innovation Center for Building Energy Saving and Construct Technology (Grant No. SJXTY1612). 


\section{References}

[1] Shannag MJ. High-performance cementitious grouts for structural repair. Cement and Concrete Research 2002; 32(5):803-808.

[2] Mohammed S, Bassuoni MT, Jacek K, Amanuddin AK. Effect of Nanosilica on rheology, fresh properties, and strength of cement-based grouts. Journal of Materials in Civil Engineering 2015; 27(4):1422-1433.

[3] Mustafa S. The effect of replacement rate and fineness of natural zeolite on the rheological properties of cement-based grouts. Canadian Journal of Civil Engineering 2008; 35(8):796-806.

[4] Huang Z, Richard Liew JY, Li W. Evaluation of compressive behavior of ultra-lightweight cement composite after elevated temperature exposure. Construction and Building Materials 2017: 148: 579-589.

[5] Huang Z, Padmaja K, Li S, Richard Liew JY. Mechanical properties and microstructure of ultra-lightweight cement composites with fly ash cenospheres after exposure to high temperatures. Construction and Building Materials 2018:164:760-774.

[6] Li Q, Liu L, Huang Z, Yuan G. Residual compressive strength of cement-based grouting material with early ages after fire. Construction and Building Materials, 2017:138:316-325.

[7] Shen D, Shi X, Zhu S, Duan X, Zhang J. Relationship between tensile Young's modulus and strength of fly ash high strength concrete at early age. Construction and Building Materials. $2016 ; 123: 317-326$.

[8] Zhou Y, Gao J, Sun Z, Qu W. A fundamental study on compressive strength, static and dynamic elastic moduli of young concrete. Construction and Building Materials 2015; 98:137-145.

[9] Li G, Zhao Y, Pang S, Li Y. Effective Young's modulus estimation of concrete. Cement and Concrete Research 1999; 29:1455-1462.

[10] Vilardell J, Aguado A, Agullo L, Gettu R. Estimation of the modulus elasticity for dam concrete. Cement and Concrete Research 1998; 28(1):93-101.

[11] Yoshitake I, Rajabipour F, Mimura Y, Scanlon A. A prediction method of tensile Young's modulus of concrete at early age. Advances in Civil Engineering 2012; 1-10. 
[12] Shariq M, Prasad J, Abbas H. Effect of GGBFS on age dependent static modulus of elasticity of concrete. Construction and Building Materials 2013; 41:411-418.

[13] Li F, Zhou S, Chen S. Influence of heat-hot environment on modulus of cement grouting material. Concrete 2015, 5:10-13 (in Chinese).

[14] Crouch LK, Pitt J, Hewitt R. Aggregate effects on pervious Portland cement concrete static modulus of elasticity. Journal of Materials in Civil Engineering 2007; 19(7):561-568.

[15] Parra C, Valcuende M, Gómez F. Splitting tensile strength and modulus of elasticity of self-compacting concrete. Construction and Building Materials 2011; 25(1):201-207.

[16] Wongpa J, Kiattikomol K, Jaturapitakkul C, Chindaprasirt P. Compressive strength, modulus of elasticity, and water permeability of inorganic polymer concrete. Materials and Design 2010; 31(10):4748-4754.

[17] Hager I. Behaviour of cement concrete at high temperature. Bulletin of the Polish Academy of Sciences: Technical Sciences 2013; 61(1):145-154.

[18] Evandro T, Fernando SL, Silva GAM, Rigoda CA, Wander LV. Effects of high temperature on the residual performance of Portland cement concretes. Materials Research 2002; 5(3):301-307.

[19] Zhen Y, Huang J, Wang D, Yang D. Experimental research on mechanical properties of lining concretes of different grade at elevated temperature. Structural Engineers 2010; 26(5):104-110 (in Chinese).

[20] Kim GY, Kim YS, Lee TG. Mechanical properties of high-strength concrete subjected to high temperature by stressed test. Transactions of Noferrous Metals Society of China (English Edition) 2009; 19(1):128-133.

[21] Hager I, Mroz K. An overview of concrete modulus of elasticity evolution with temperature and comments to European code provisions. International Fire Safety Symposium Coimbra, Portugal, April 2015.

[22] Kodur V. Properties of concrete at elevated temperatures. International Scholarly Research Notices 2014; 1-15.

[23] Wei H, Zhang Z. Study of countermeasure on fire extinguishing of super high-rise building through CCTV conflagration. Fire Science and Technology 2010; 29(7): 606- 612.

[24] Zhang L, Dong X, Xu J. Reinforcing and Retrofitting of an Office Building in Wuhan Optical 
Valley after Fire Accident. Building Structure 2007; 37(9):132-133.

[25] MOC (Ministry of Construction) (2015): GB/T 50448-2015. Technical code for application of cementitious grout. MOC, Beijing, China.

[26] Niu Y, Zhang S, Robert YL, Tu Ch. Modeling of thermo-mechanical damage of early-age concrete. Journal of Structural Engineering 1995; 121(4):717-726.

[27] Li N, Shi X, Xiao M. Experimental investigation on compressive strength decaying behaviors of concrete after elevated temperature. Building Science 2007; 23(9):58-61 (in Chinese).

[28] Aydm S, Baradan B. Effect of pumice and fly ash incorporation on high temperature resistance of cement based mortars. Cement and Concrete Research 2007; 37(6):988-995.

[29] MOC (Ministry of Construction) (2002): GB/T 50081-2002. Standard for test method of mechanical properties on ordinary concrete. MOC, Beijing, China.

[30] Committee for Standardization, Eurocode 2: Design of concrete structures, Brussels, Belgium, 2004.

[31] American Concrete Institute, ACI-216-07 Code Requirements for Determining Fire Resistance of Concrete and Masonry Construction Assemblies, Farmington Hills, USA, 2007.

[32] Construction Ministry of Guangdong Province (2010): DBJT15-81-2011. Code for Fire Resistance Design of Concrete Building Structures. Construction Ministry of Guangdong Province, Guangdong, China. 


\section{Figure and table captions}

Table 1 Mix design of the cement-based grouting material (CGM-1).

Table 2 Properties of the high-strength cement grouting material (CGM-1).

Table 3 Chemical composition of additive binding gelled material.

Table 4 The test conditions for each specimen's group.

Table 5 Residual elastic moduli $\left(E_{c}, T\right)$ of the specimens tested under different conditions $\left(\times 10^{3}\right.$ $\mathrm{MPa})$.

Fig. 1 Elasticity modulus test setup.

Fig. 2 The comparisons of the degradation ratio of residual elastic modulus $\left(E_{c, T} / E_{c, 20}\right)$ against the different curing ages before heating for the specimens under natural cooling condition.

Fig. 3 The comparisons of the degradation ratio of residual elastic modulus $\left(E_{c, T} / E_{c, 20}\right)$ against the different curing ages before heating for the specimens under water cooling condition.

Fig. 4 The degradation ratio of residual elastic modulus $\left(E_{c, T} / E_{c, 20}\right)$ against temperature for the specimens with different curing ages $(\mathrm{d}=$ day) before heating under natural cooling condition.

Fig. 5 The degradation ratio of residual elastic modulus $\left(E_{c, T} / E_{c, 20}\right)$ against temperature for the specimens with different curing ages $(\mathrm{d}=$ day) before heating under water cooling condition.

Fig. 6 The residual elastic modulus $\left(E_{c, T}\right)$ against the water mixing ratio for the specimens with different curing ages before heating under natural cooling condition.

Fig. 7 The residual elastic modulus $\left(E_{c, T}\right)$ against the water mixing ratio for the specimens with different curing ages before heating under water cooling condition.

Fig. 8 The influence of cooling methods on the degradation ratio of residual elastic modulus $\left(E_{c, T} / E_{c}, 20\right)$ for the specimens under different conditions.

Fig. 9 The comparisons of the degradation of the residual elastic modulus of the material (CGM) between the test data and predictions from the different codes. 
Tables:

Table 1 Mix design of the cement-based grouting material (CGM-1)

\begin{tabular}{lcccc}
\hline Composition & High-strength cement & Quartz sand & Water reducing agent & Expanding agent \\
\hline Content (wt. \%) & 50 & 48.9 & 1 & 0.1 \\
\hline
\end{tabular}

Table 2 Properties of the high-strength cement grouting material (CGM-1)

\begin{tabular}{lccccc}
\hline \multirow{2}{*}{ Density } & Fluidity & $\begin{array}{c}\text { Vertical } \\
\text { Expansion rate }\end{array}$ & $\begin{array}{c}\text { Compressive } \\
\text { strength (1 day) }\end{array}$ & $\begin{array}{c}\text { Compressive } \\
\text { strength (3 days) }\end{array}$ & Size of quartz sand \\
\hline $2200 \mathrm{~kg} / \mathrm{m}^{3}$ & $\geq 300 \mathrm{~mm}$ & $\geq 0.02 \%$ & $\geq 30 \mathrm{MPa}$ & $\geq 45 \mathrm{MPa}$ & $5 \mu$ to $5 \mathrm{~mm}$ \\
\hline
\end{tabular}

Table 3 Chemical composition of additive binding gelled material

\begin{tabular}{ccccccccccc}
\hline Composition & $\mathrm{Na}_{2} \mathrm{O}$ & $\mathrm{MgO}$ & $\mathrm{Al}_{2} \mathrm{O}_{3}$ & $\mathrm{SiO}_{2}$ & $\mathrm{SO}_{3}$ & $\mathrm{~K}_{2} \mathrm{O}$ & $\mathrm{CaO}$ & $\mathrm{TiO}_{2}$ & $\mathrm{Fe}_{2} \mathrm{O}_{3}$ & $\mathrm{LOI}$ \\
Content (wt. \%) & 0.38 & 3.72 & 7.26 & 18.99 & 5.85 & 0.807 & 51.49 & 0.304 & 2.615 & 8.59 \\
\hline
\end{tabular}

Table 4 The test conditions for each specimen's group

Water mixing ratio (wt. \%) Heating temperature $\left({ }^{0} \mathrm{C}\right) \quad$ Cooling methods $\quad$ Curing age before heating (day)

\begin{tabular}{|c|c|c|c|}
\hline $14 \%$ & $150, \quad 350, \quad 550$ & $\begin{array}{l}\text { Natural cooling, } \\
\text { water cooling }\end{array}$ & $3, \quad 7, \quad 14, \quad 28$ \\
\hline
\end{tabular}


Table 5 Residual elastic moduli $\left(E_{c}, T\right)$ of the specimens tested under different conditions $\left(\times 10^{3}\right.$ $\mathrm{MPa})$

\begin{tabular}{|c|c|c|c|c|c|c|}
\hline \multirow{2}{*}{$\begin{array}{l}\text { Water mixing ratio } \\
\text { (wt. \%) }\end{array}$} & \multirow{2}{*}{$\begin{array}{c}\text { Heating } \\
\text { temperature }\left({ }^{0} \mathrm{C}\right)\end{array}$} & \multirow{2}{*}{ Cooling methods } & \multicolumn{4}{|c|}{ Curing age before heating } \\
\hline & & & 3 days & 7 days & 14 days & 28 days \\
\hline \multirow{6}{*}{12} & \multirow{2}{*}{150} & Natural cooling & 28.42 & 30.33 & 27.40 & 27.35 \\
\hline & & Water cooling & 28.90 & 31.74 & 28.19 & 26.39 \\
\hline & \multirow{2}{*}{350} & Natural cooling & 21.45 & 21.57 & 20.37 & 19.36 \\
\hline & & Water cooling & 21.85 & 24.93 & 20.62 & 19.07 \\
\hline & \multirow{2}{*}{550} & Natural cooling & 17.22 & 18.12 & 15.66 & 15.43 \\
\hline & & Water cooling & 17.46 & 19.64 & 16.91 & 15.29 \\
\hline \multirow{6}{*}{14} & \multirow{2}{*}{150} & Natural cooling & 23.90 & 26.33 & 23.52 & 22.10 \\
\hline & & Water cooling & 25.20 & 28.74 & 24.40 & 21.50 \\
\hline & \multirow{2}{*}{350} & Natural cooling & 17.75 & 19.13 & 17.62 & 15.42 \\
\hline & & Water cooling & 19.30 & 20.93 & 18.75 & 16.42 \\
\hline & \multirow{2}{*}{550} & Natural cooling & 13.34 & 14.74 & 12.57 & 12.31 \\
\hline & & Water cooling & 15.85 & 16.74 & 14.56 & 11.85 \\
\hline \multirow{6}{*}{16} & \multirow{2}{*}{150} & Natural cooling & 20.56 & 25.19 & 20.19 & 19.96 \\
\hline & & Water cooling & 23.18 & 26.96 & 22.97 & 19.77 \\
\hline & \multirow{2}{*}{350} & Natural cooling & 16.67 & 18.10 & 15.17 & 14.91 \\
\hline & & Water cooling & 16.83 & 18.87 & 15.62 & 14.70 \\
\hline & \multirow{2}{*}{550} & Natural cooling & 10.90 & 13.15 & 10.08 & 11.28 \\
\hline & & Water cooling & 13.38 & 15.34 & 12.33 & 9.68 \\
\hline
\end{tabular}


Figures:

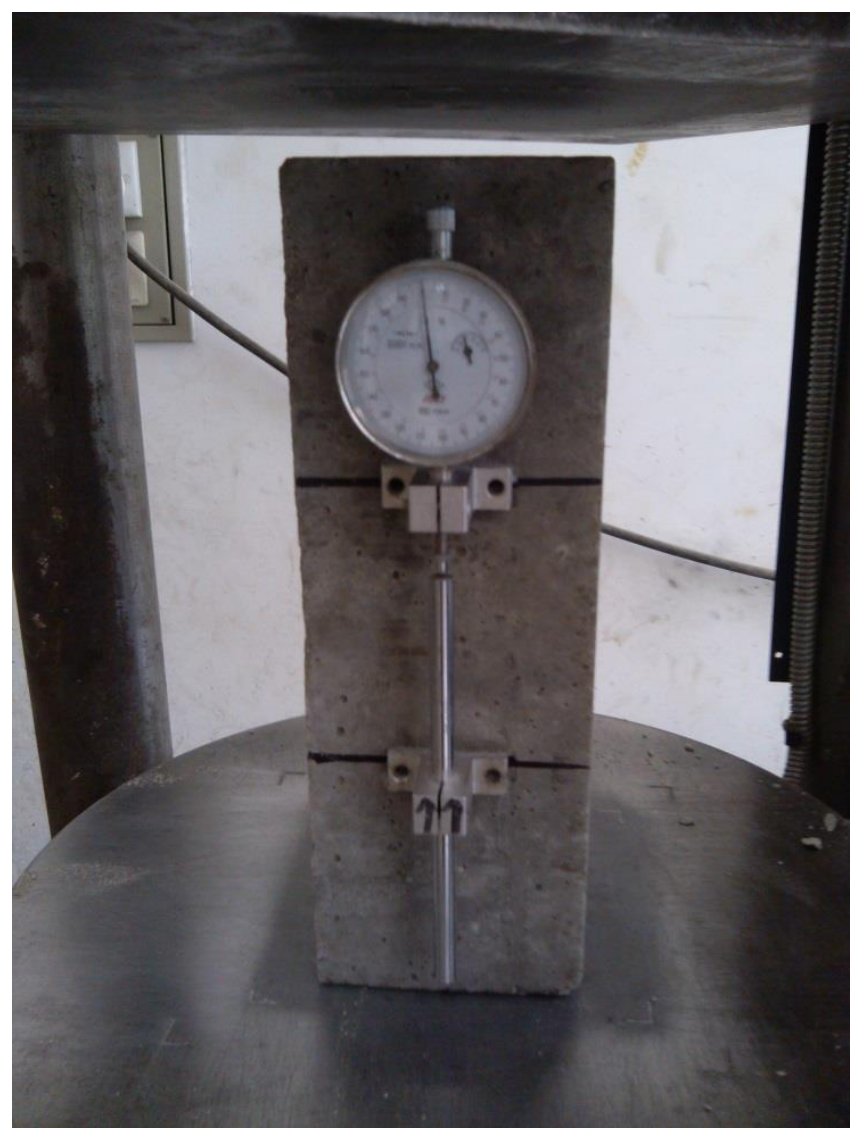

(a)

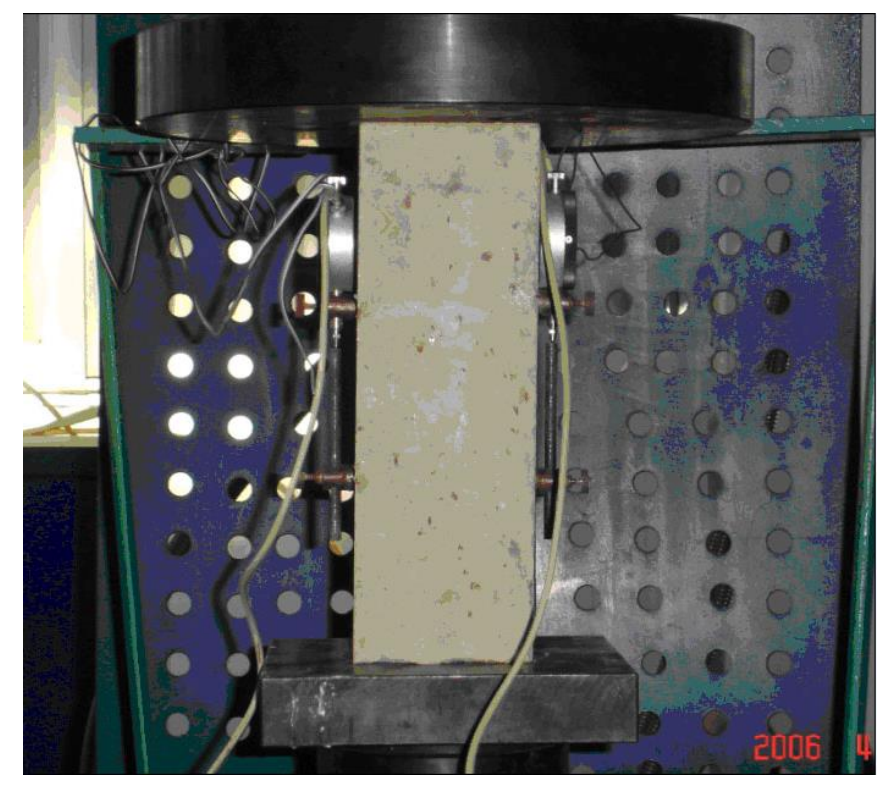

(b)

Fig. 1 Elasticity modulus test setup. 


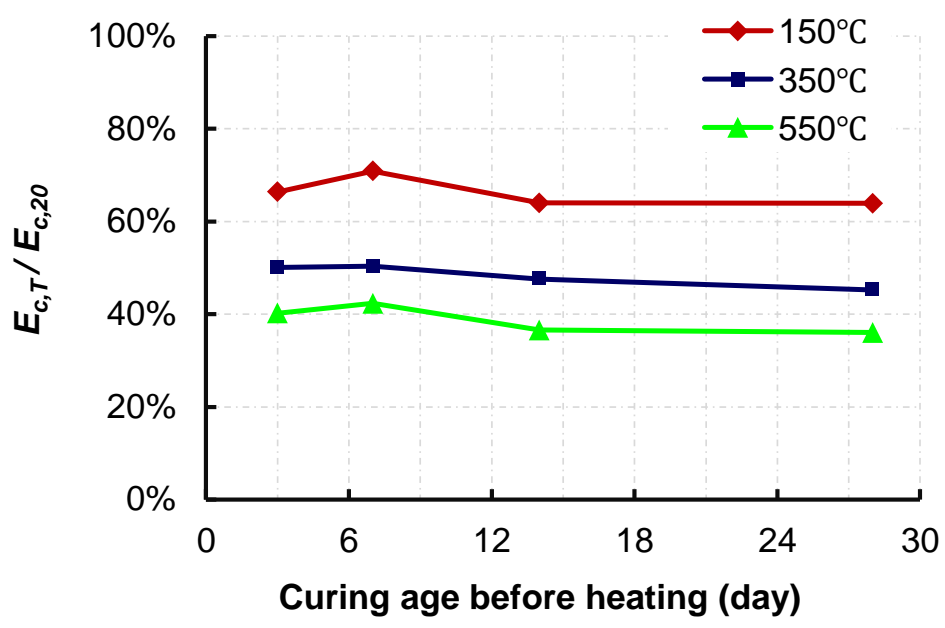

(a) Water mixing ratio of $12 \%$

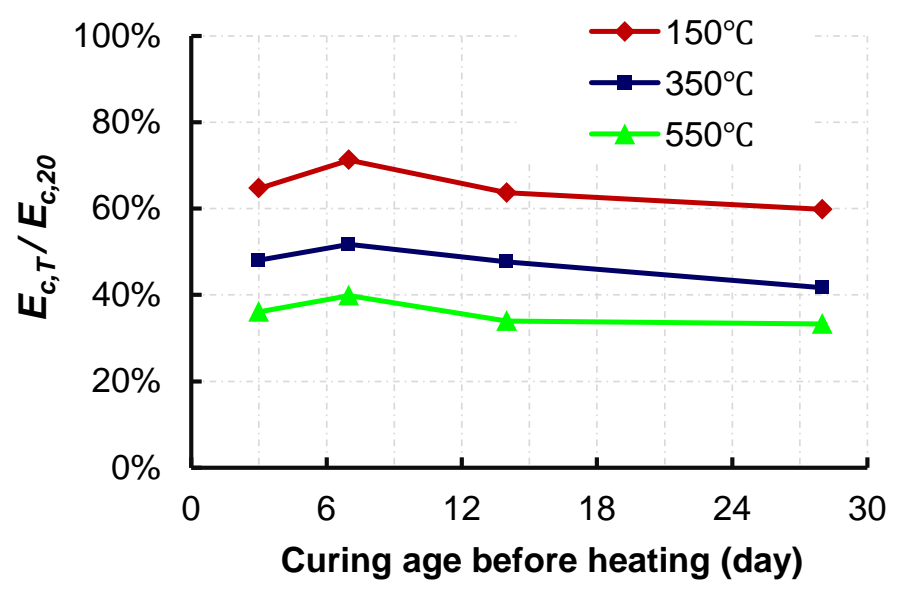

(b) Water mixing ratio of $14 \%$

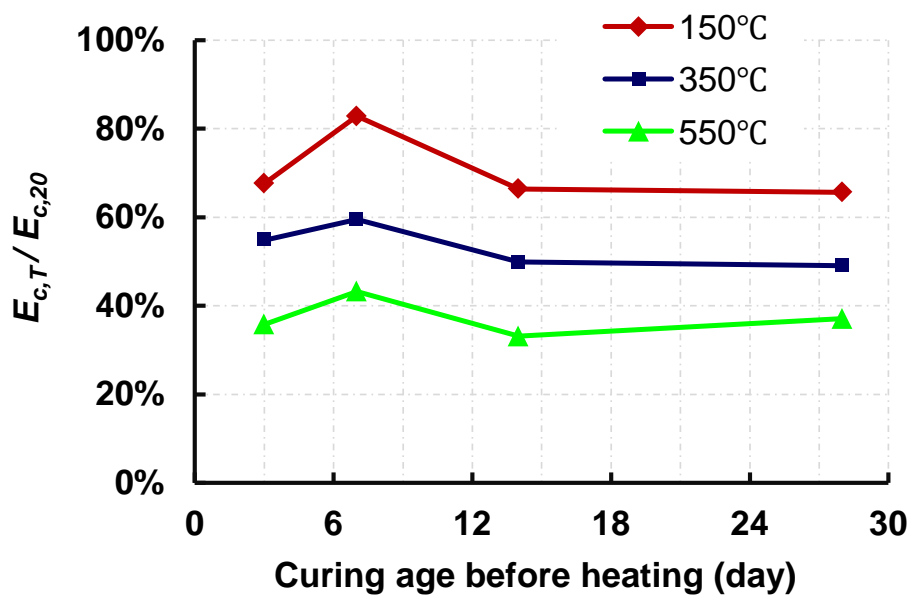

(a) Water mixing ratio of $16 \%$

Fig. 2 The comparisons of the degradation ratio of residual elastic modulus $\left(E_{c}, T / E_{c, 20}\right)$ against the different curing ages before heating for the specimens under natural cooling condition. 


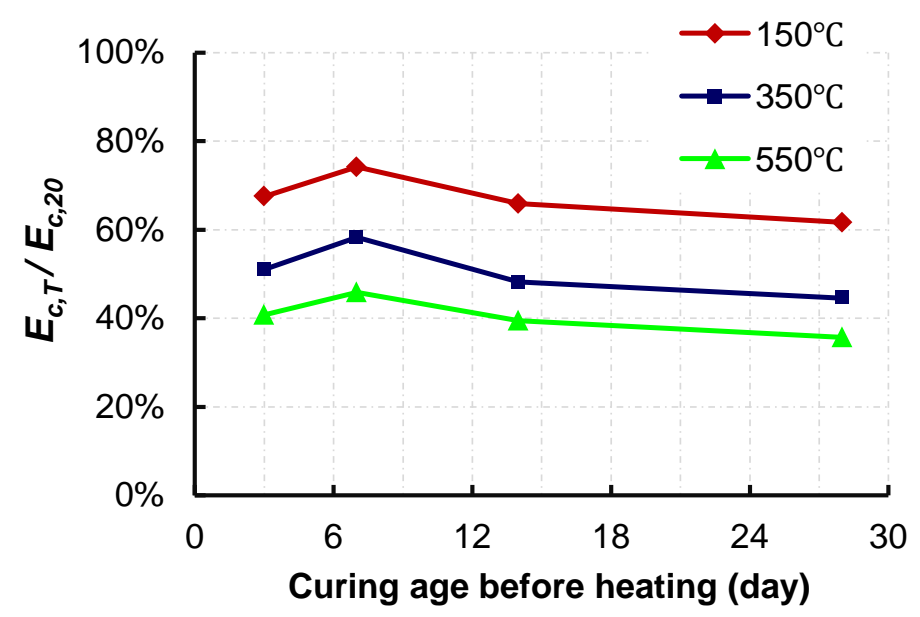

(a) Water mixing ratio of $12 \%$

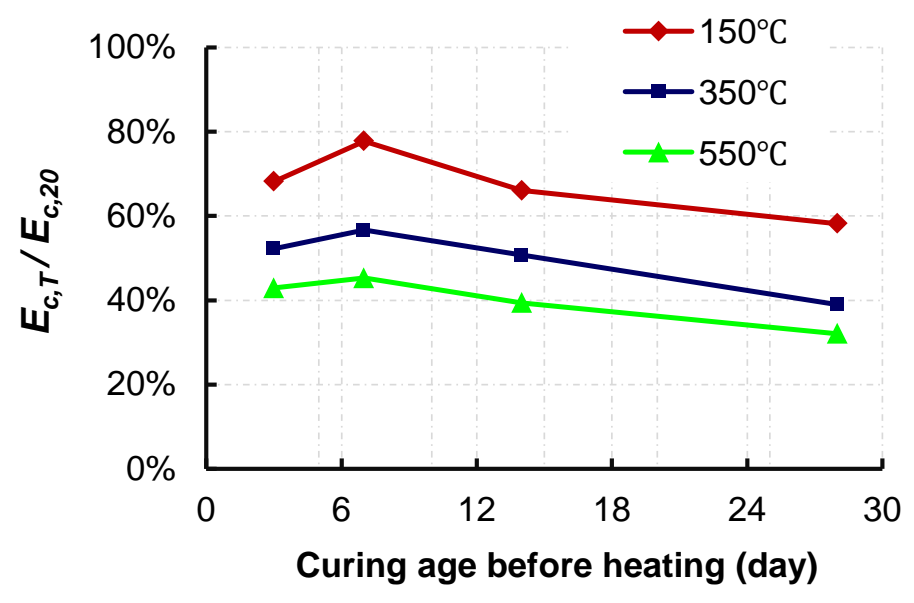

(b) Water mixing ratio of $14 \%$

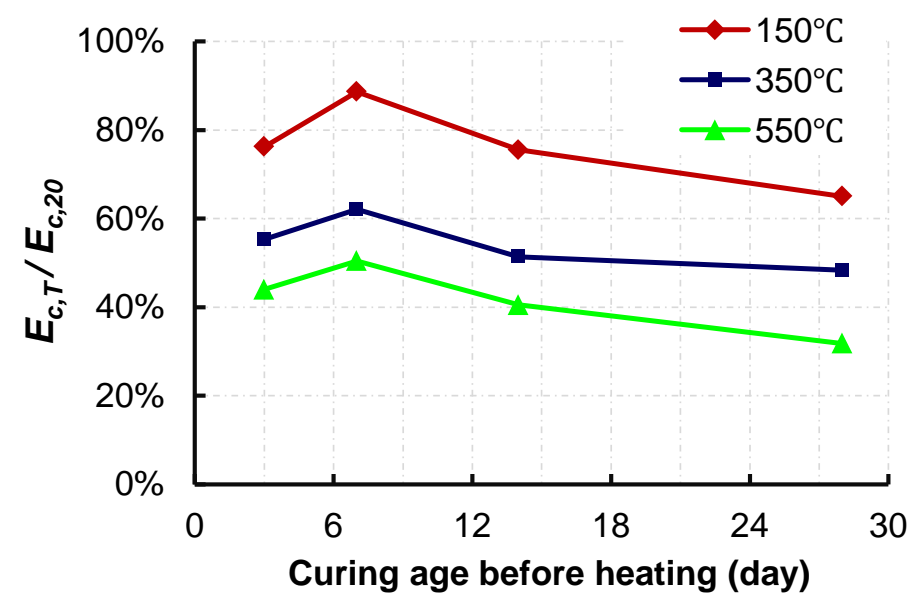

(c) Water mixing ratio of $16 \%$

Fig. 3 The comparisons of the degradation ratio of residual elastic modulus $\left(E_{c, T} / E_{c, 20}\right)$ against the different curing ages before heating for the specimens under water cooling condition. 


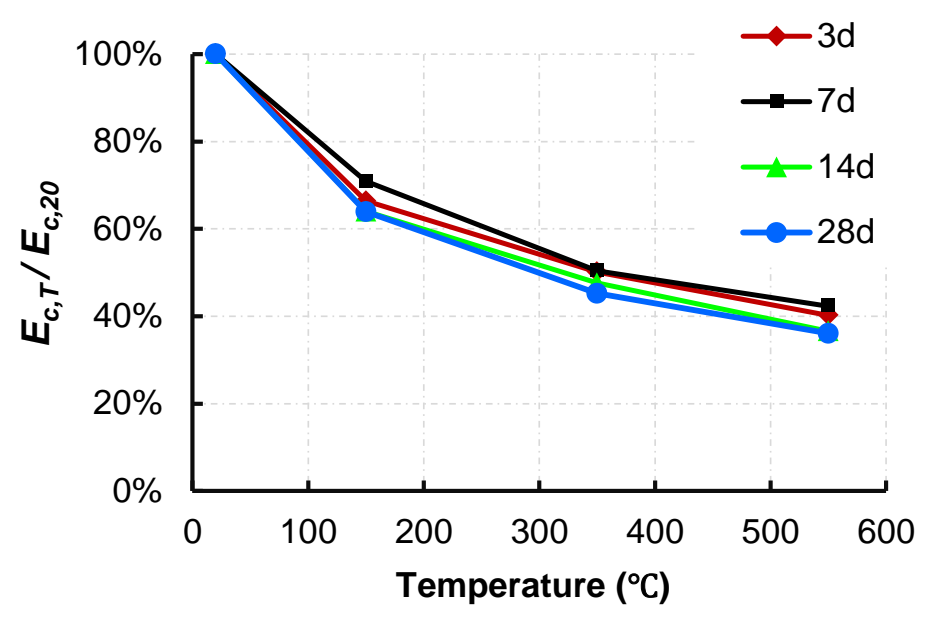

(a) Water mixing ratio of $12 \%$

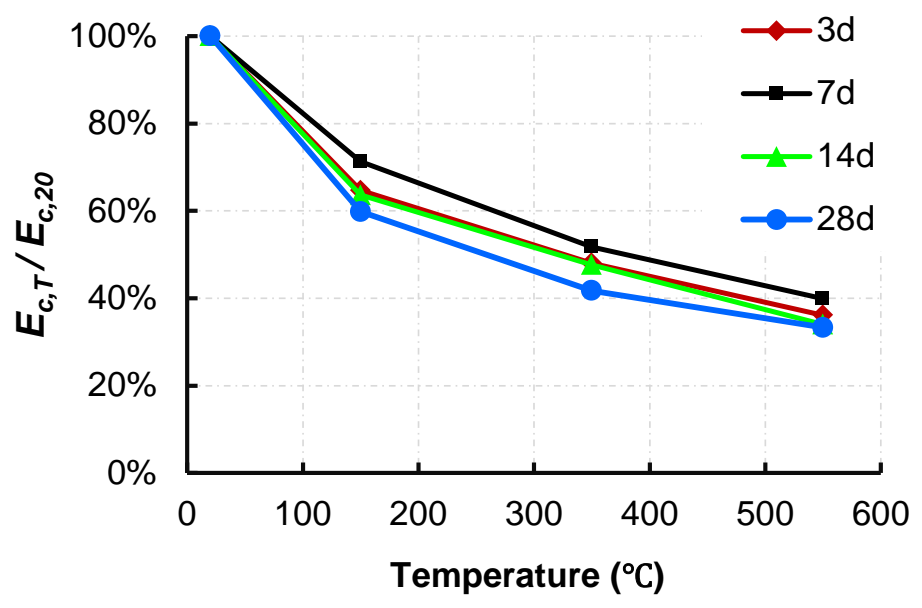

(b) Water mixing ratio of $14 \%$

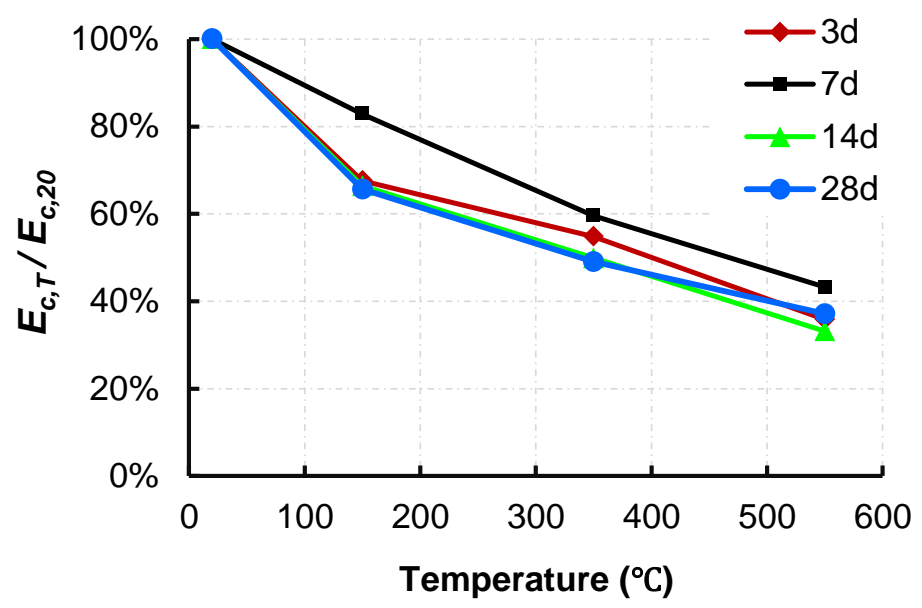

(c) Water mixing ratio of $16 \%$

Fig. 4 The degradation ratio of residual elastic modulus $\left(E_{c, T} / E_{c, 20}\right)$ against temperature for the specimens with different curing ages $(\mathrm{d}=$ day) before heating under natural cooling condition. 


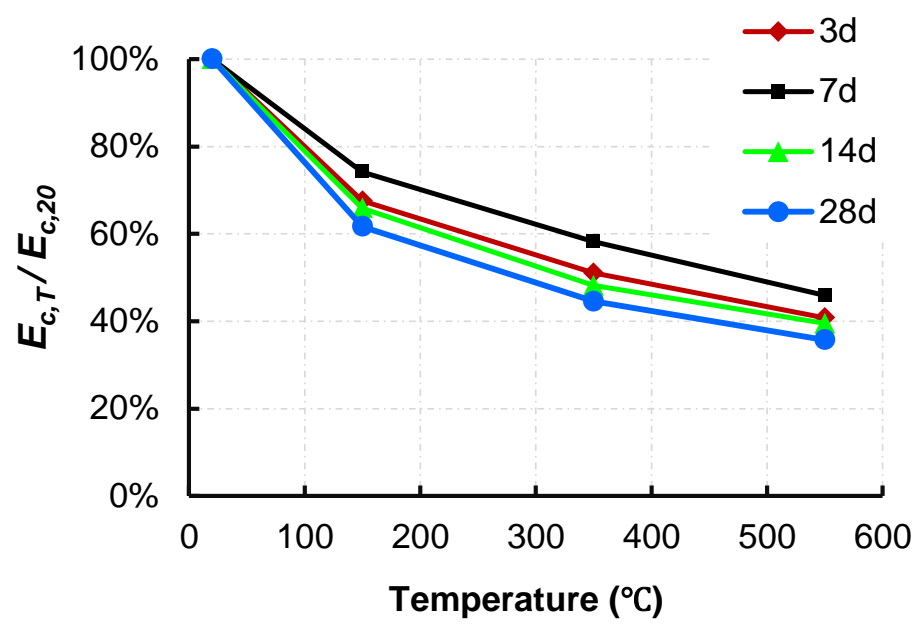

(a) Water mixing ratio of $12 \%$

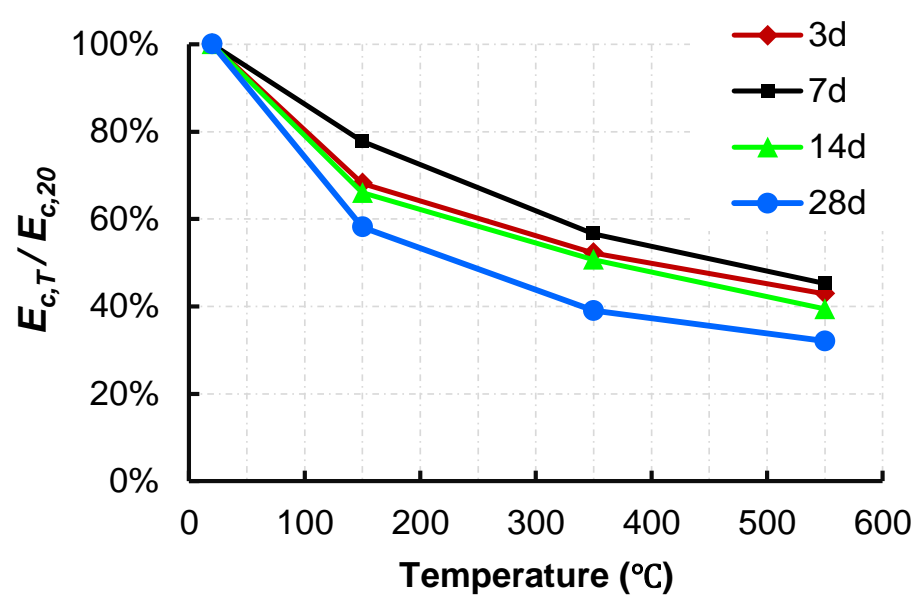

(b) Water mixing ratio of $14 \%$

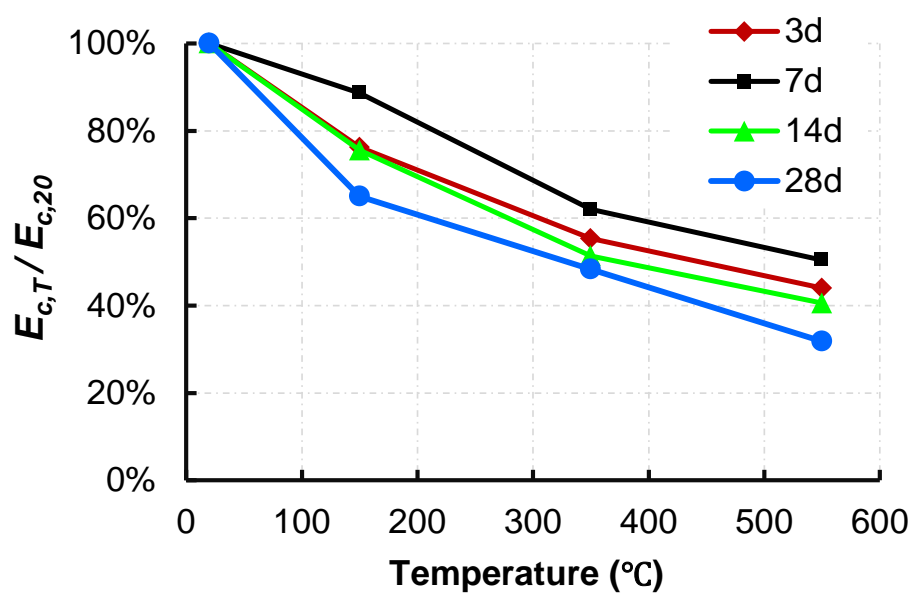

(c) Water mixing ratio of $16 \%$

Fig. 5 The degradation ratio of residual elastic modulus $\left(E_{c, T} / E_{c, 20}\right)$ against temperature for the specimens with different curing ages $(\mathrm{d}=$ day) before heating under water cooling condition. 


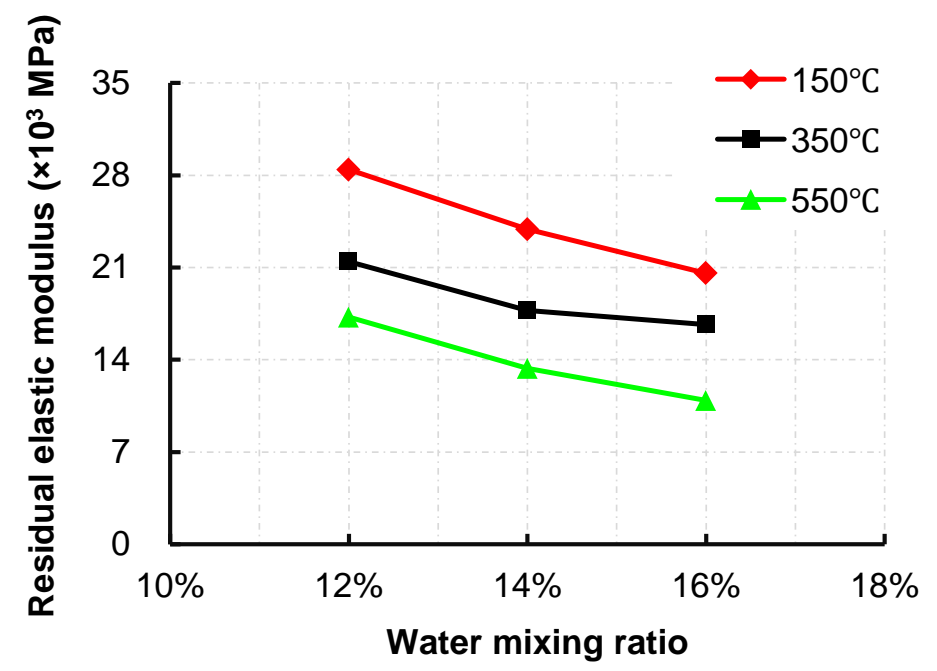

(a) 3 days curing age before heating

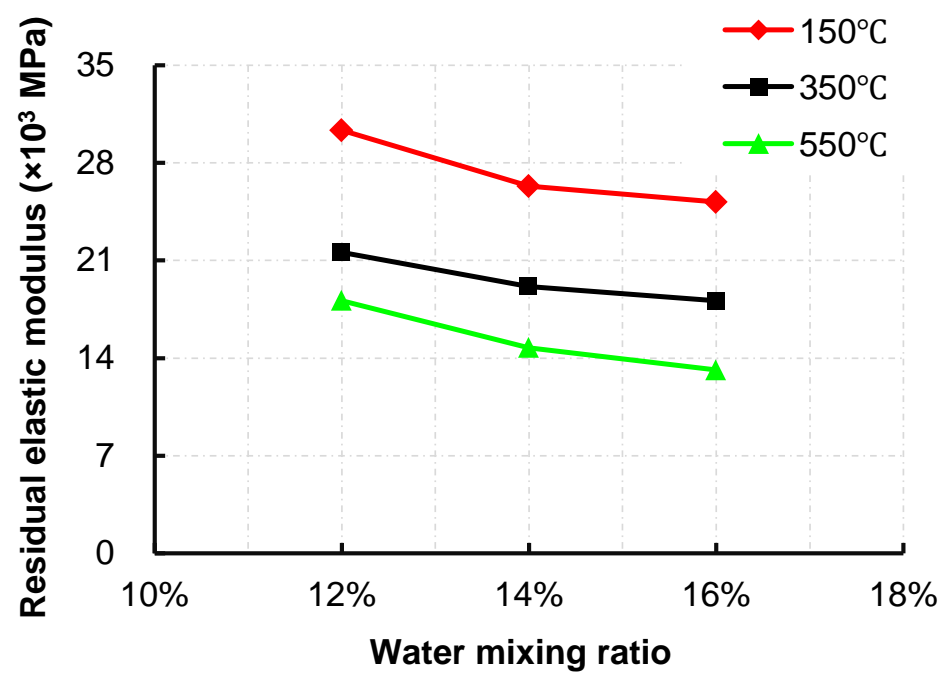

(b) 7 days curing age before heating 


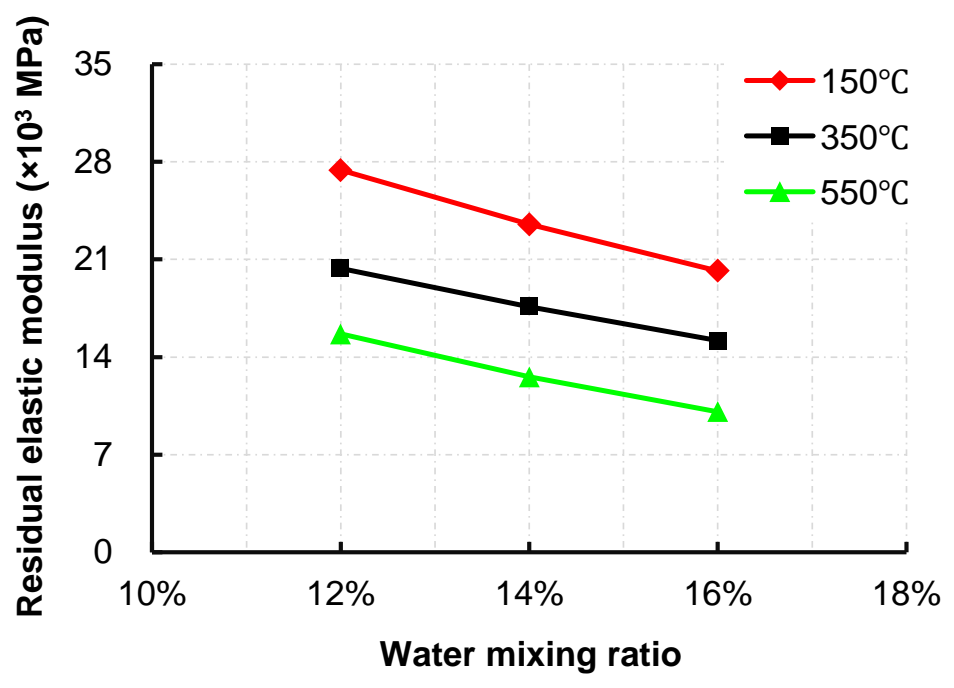

(c) 14 days curing age before heating

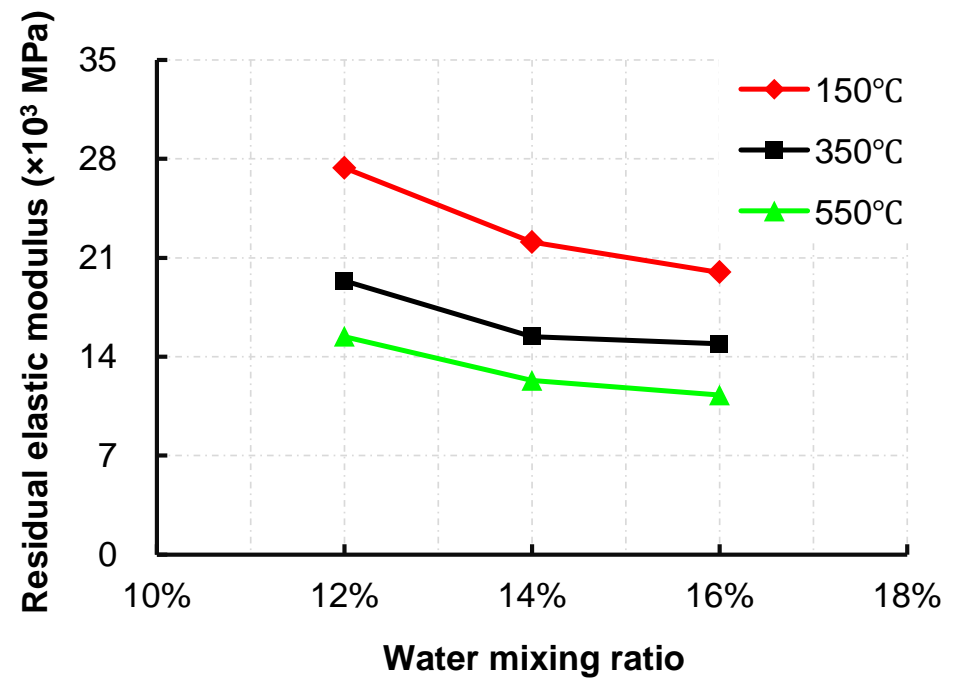

(d) 28 days curing age before heating

Fig. 6 The residual elastic modulus $\left(E_{c, T}\right)$ against the water mixing ratio for the specimens with different curing ages before heating under natural cooling condition. 


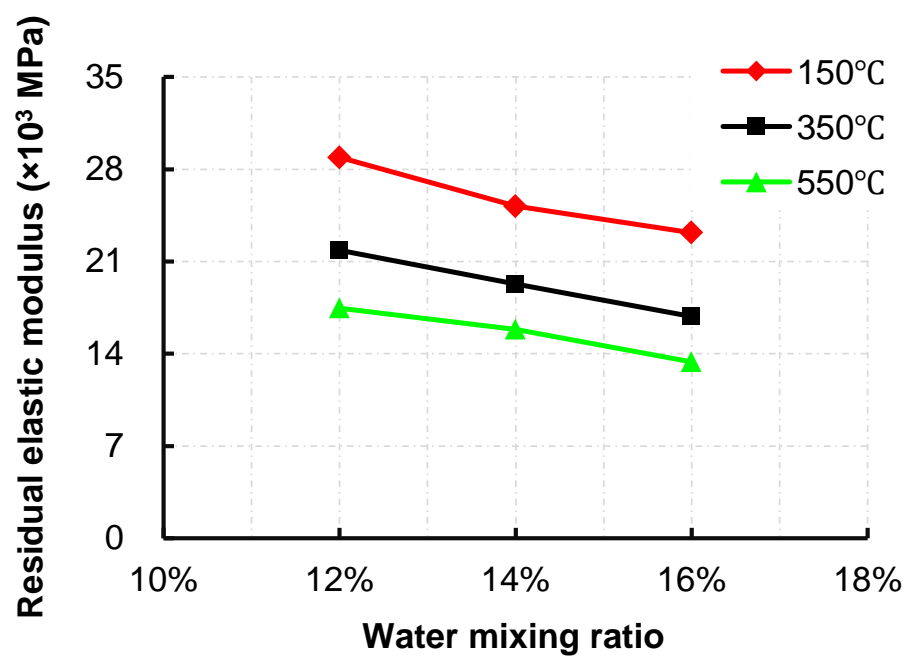

(a) 3 days curing age before heating

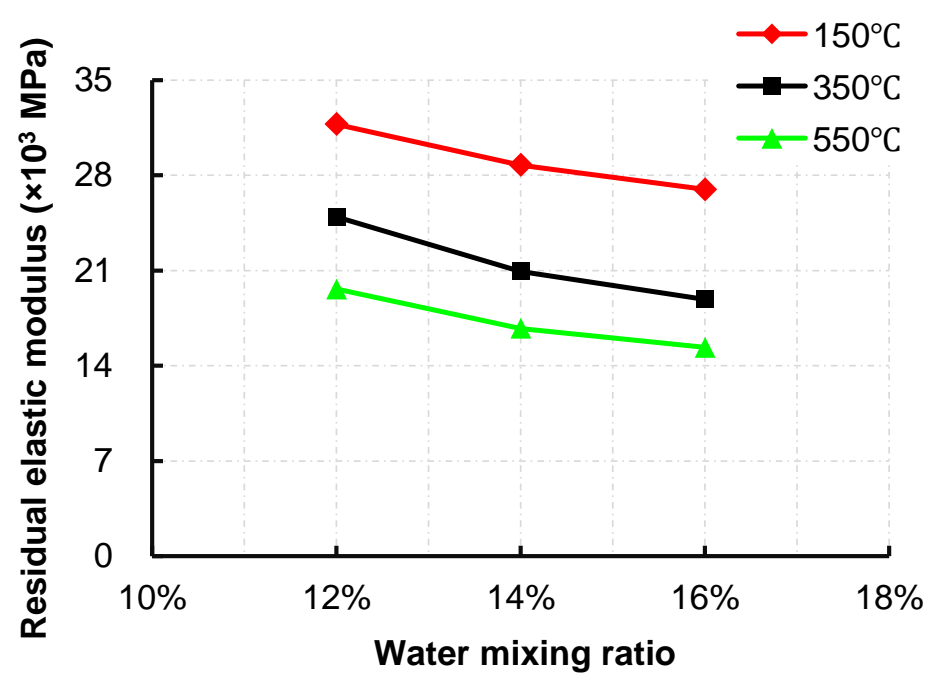

(b) 7 days curing age before heating 


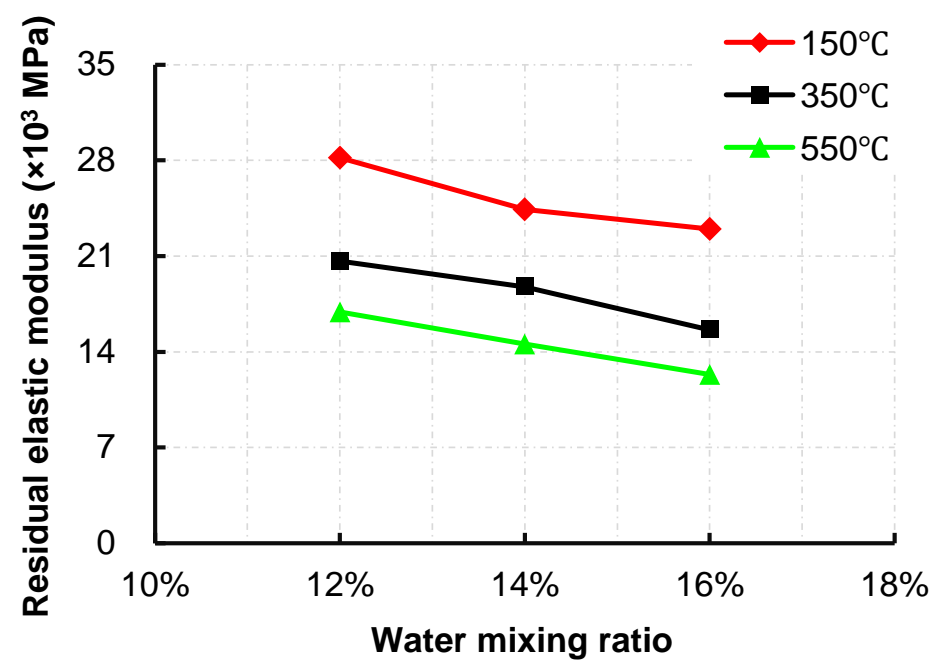

(c) 14 days curing age before heating

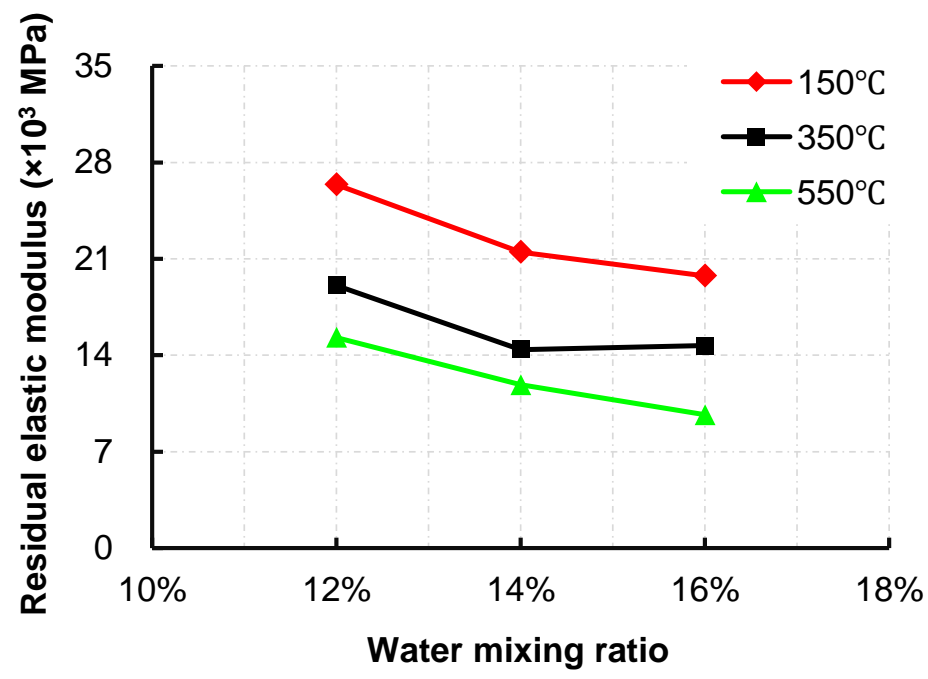

(d) 28 days curing age before heating

Fig. 7 The residual elastic modulus $\left(E_{c, T}\right)$ against the water mixing ratio for the specimens with different curing ages before heating under water cooling condition. 


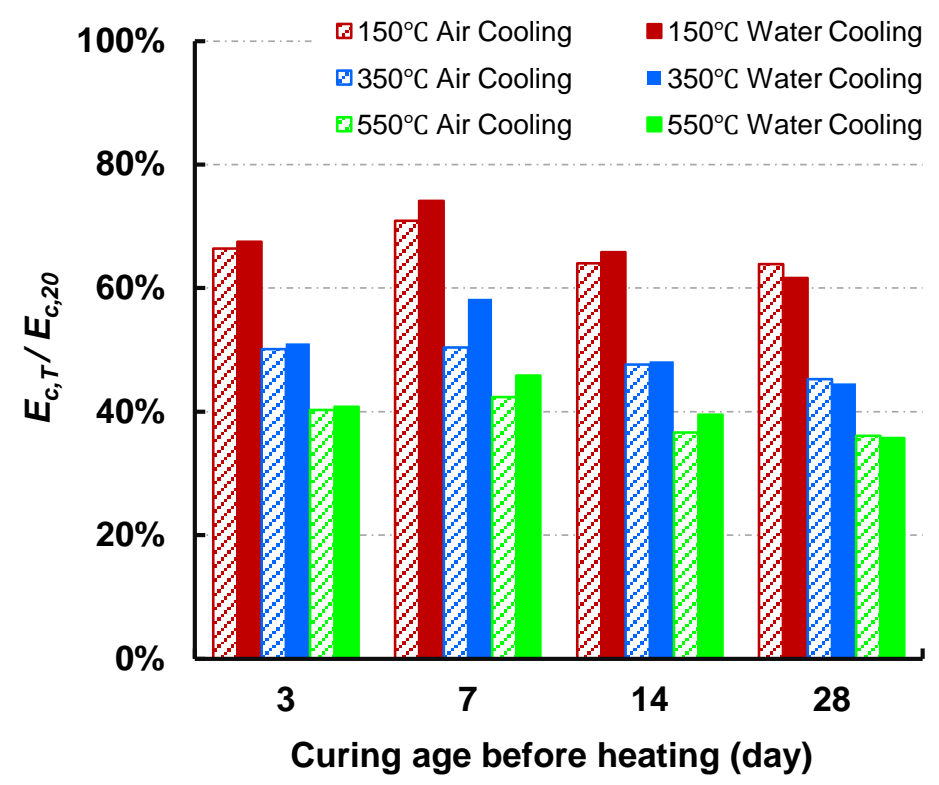

(a) Water mixing ratio of $12 \%$

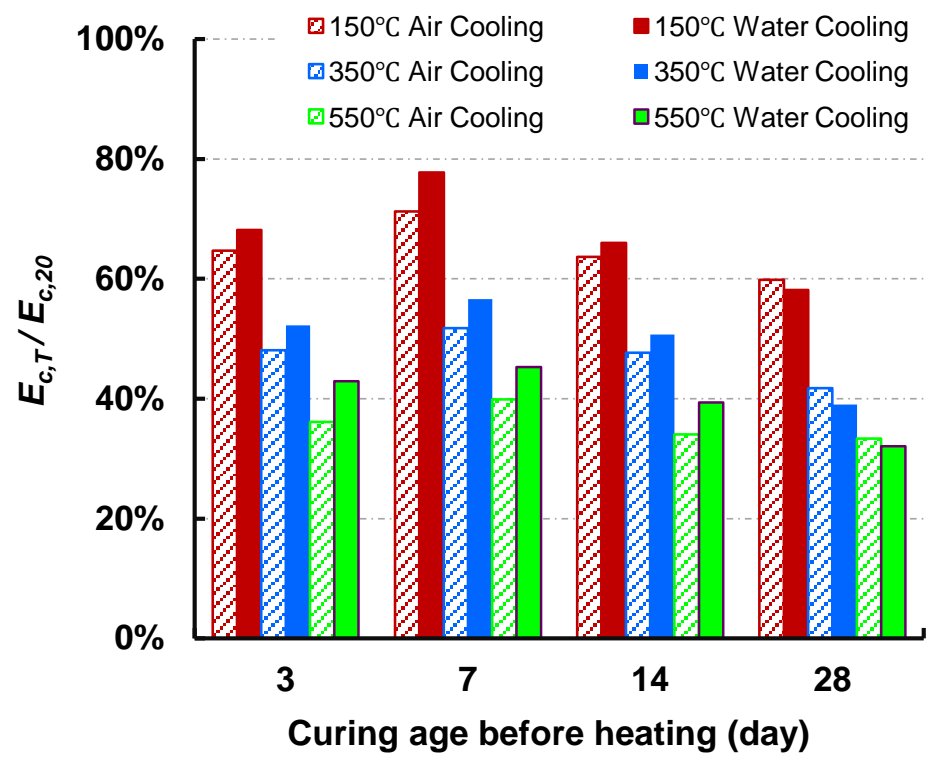

(b) Water mixing ratio of $14 \%$ 


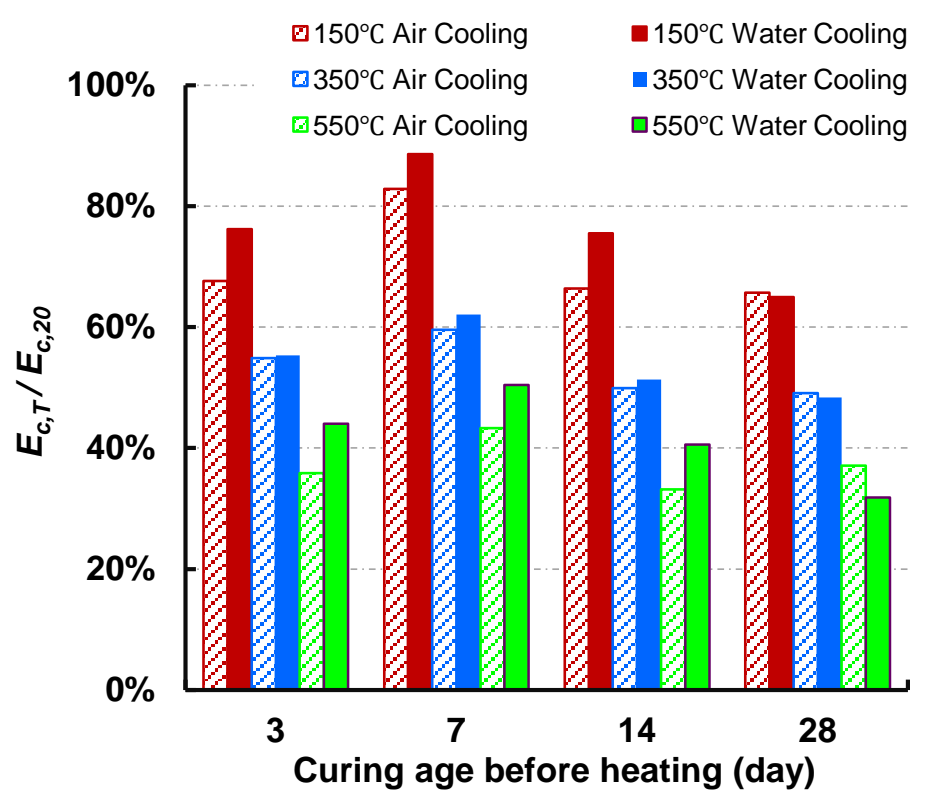

(c) Water mixing ratio of $16 \%$

Fig. 8 The influence of cooling methods on the degradation ratio of residual elastic modulus $\left(E_{c}, T\right.$ $\left./ E_{c, 20}\right)$ for the specimens under different conditions.

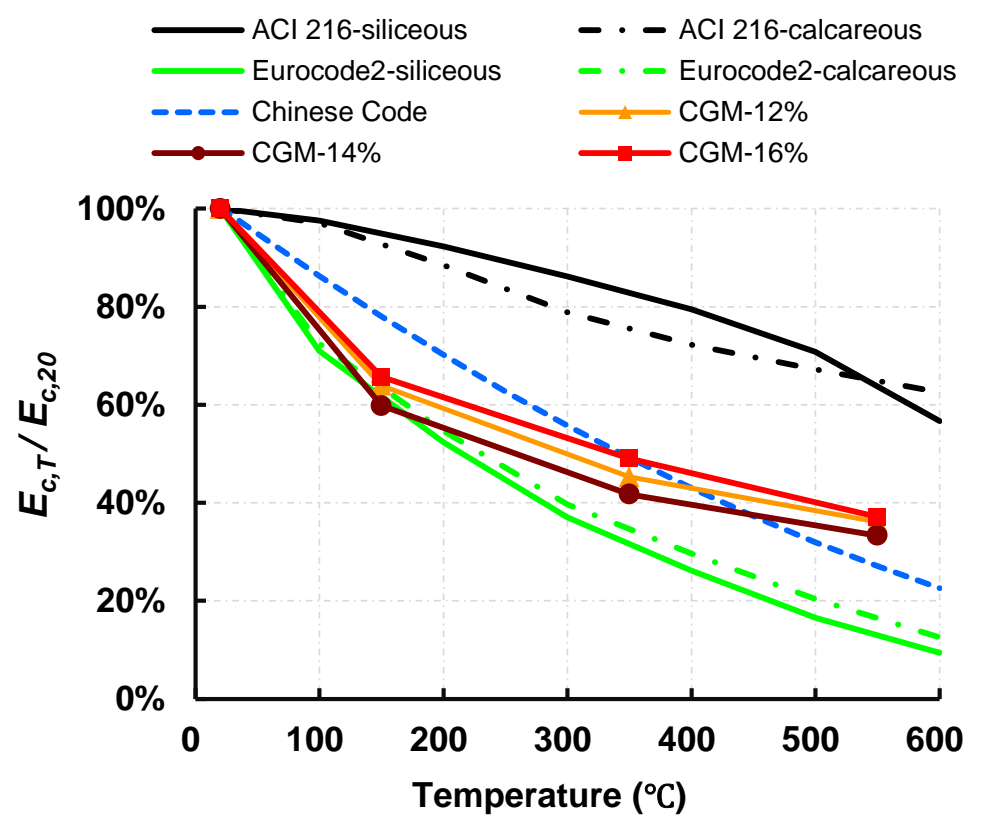

(a) Natural cooling 


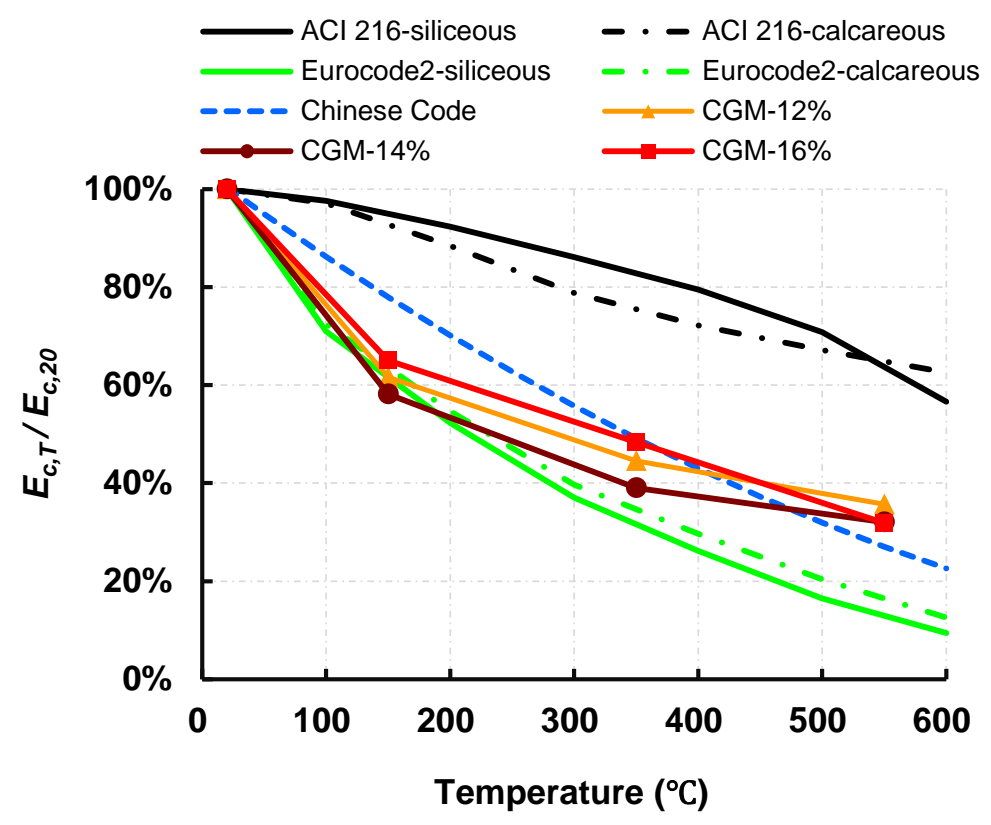

(b) Water cooling

Fig. 9 The comparisons of the degradation of the residual elastic modulus of the material (CGM) between the test data and predictions from the different codes. 